\title{
The product of microbial uranium reduction includes multiple species with U(IV)-phosphate coordination
}

\author{
Daniel S. Alessi ${ }^{\mathrm{a}, 1}$, Juan S. Lezama-Pacheco ${ }^{\mathrm{b}}$, Joanne E. Stubbs ${ }^{\mathrm{b}, 2}$, \\ Markus Janousch ${ }^{\mathrm{c}}$, John R. Bargar ${ }^{\mathrm{b}}$, Per Persson ${ }^{\mathrm{d}}$, Rizlan Bernier-Latmani ${ }^{\mathrm{a}, *}$ \\ ${ }^{a}$ Environmental Microbiology Laboratory, Ecole Polytechnique Fédérale de Lausanne, CH-1015 Lausanne, Switzerland \\ ${ }^{\mathrm{b}}$ Chemistry and Catalysis Division, Stanford Synchrotron Radiation Lightsource, SLAC National Accelerator Laboratory, Menlo Park, \\ CA 94025, USA \\ ${ }^{\mathrm{c}}$ Swiss Light Source, Paul Scherrer Institut, Villigen, CH-5232 Villigen PSI, Switzerland \\ ${ }^{\mathrm{d}}$ Department of Chemistry, Umeå University, SE-90187 Umeå, Sweden
}

Received 14 September 2013; accepted in revised form 8 January 2014; Available online 30 January 2014

\begin{abstract}
Until recently, the reduction of $\mathrm{U}(\mathrm{VI})$ to $\mathrm{U}(\mathrm{IV})$ during bioremediation was assumed to produce solely the sparingly soluble mineral uraninite, $\mathrm{UO}_{2(\mathrm{~s})}$. However, results from several laboratories reveal other species of $\mathrm{U}(\mathrm{IV})$ characterized by the absence of an EXAFS U-U pair correlation (referred to here as noncrystalline U(IV)). Because it lacks the crystalline structure of uraninite, this species is likely to be more labile and susceptible to reoxidation. In the case of single species cultures, analyses of $U$ extended X-ray fine structure (EXAFS) spectra have previously suggested U(IV) coordination to carboxyl, phosphoryl or carbonate groups. In spite of this evidence, little is understood about the species that make up noncrystalline U(IV), their structural chemistry and the nature of the U(IV)-ligand interactions. Here, we use infrared spectroscopy (IR), uranium $\mathrm{L}_{\mathrm{III}}$-edge $\mathrm{X}$-ray absorption spectroscopy (XAS), and phosphorus K-edge XAS analyses to constrain the binding environments of phosphate and uranium associated with Shewanella oneidensis MR-1 bacterial cells. Systems tested as a function of $\mathrm{pH}$ included: cells under metal-reducing conditions without uranium, cells under reducing conditions that produced primarily uraninite, and cells under reducing conditions that produced primarily biomass-associated noncrystalline U(IV). P X-ray absorption near-edge structure (XANES) results provided clear and direct evidence of U(IV) coordination to phosphate. Infrared (IR) spectroscopy revealed a pronounced perturbation of phosphate functional groups in the presence of uranium. Analysis of these data provides evidence that U(IV) is coordinated to a range of phosphate species, including monomers and polymerized networks. U EXAFS analyses and a chemical extraction measurements support these conclusions. The results of this study provide new insights into the binding mechanisms of biomass-associated U(IV) species which in turn sheds light on the mechanisms of biological U(VI) reduction. (C) 2014 Elsevier Ltd. All rights reserved.
\end{abstract}

\section{INTRODUCTION}

Uranium contamination in the subsurface remains problematic in areas of active or historic uranium mining, milling or processing. One promising strategy for the remediation of uranium aims at transforming the soluble and mobile hexavalent form of uranium, $\mathrm{U}(\mathrm{VI})$, to the reduced and relatively immobile tetravalent form, U(IV) (O'Loughlin et al., 2003; Jeon et al., 2005; Wall and Krumholz, 2006; Burgos et al., 2008; Sheng et al., 2011; Zhang et al., 2011). Until recently,

\footnotetext{
* Corresponding author. Tel.: +41 216935001.

E-mail address: rizlan.bernier-latmani@epfl.ch (R. Bernier-Latmani).

${ }^{1}$ Current address: Department of Earth and Atmospheric Sciences, University of Alberta, Edmonton, AB T5J 4B5, Canada.

${ }^{2}$ Current address: Center for Advanced Radiation Sources, University of Chicago, Chicago, IL 60637, USA.
} 
reduction of $\mathrm{U}(\mathrm{VI})$ to $\mathrm{U}(\mathrm{IV})$ was only found to produce the sparingly soluble mineral uraninite, $\mathrm{UO}_{2(\mathrm{~s})}$ (Lovley et al., 1991; Lovley and Phillips, 1992; Lovley, 1993; Burns, 1999; O'Loughlin et al., 2003; Wall and Krumholz, 2006; Burgos et al., 2008). However, recent research reveals that non-uraninite species of $\mathrm{U}(\mathrm{IV})$, i.e., those lacking the $3.85 \AA \mathrm{U}-\mathrm{U}$ pair correlation characteristic of $\mathrm{UO}_{2}$ observed using X-ray absorption spectroscopy (XAS), can form as the product of $\mathrm{U}(\mathrm{VI})$ reduction by Gram-negative and Gram-positive bacteria (Bernier-Latmani et al., 2010; Fletcher et al., 2010; Boyanov et al., 2011; Cologgi et al., 2011; Ray et al., 2011; Sivaswamy et al., 2011), by biogenic Fe(II)-bearing minerals (Veeramani et al., 2011, 2013; Latta et al., 2012), and in biostimulated or naturally reduced sediments (Campbell et al., 2011; Sharp et al., 2011). It is unknown if these U(IV) species occurs as amorphous solids or coordination polymers, as complexes sorbed to biomass functional groups, or as a mixture of the above. Because of this ambiguity, we will henceforth refer to this species as noncrystalline U(IV). Its lack of crystalline structure and its susceptibility to complexation by bicarbonate (Alessi et al., 2012), makes it more labile and prone to reoxidation than U(IV) bound in uraninite (Alessi et al., 2013; Cerrato et al., 2013). For this reason, geochemical models that assume uraninite is the sole product of $\mathrm{U}(\mathrm{VI})$ reduction may be critically flawed.

The microbial reduction of $\mathrm{U}(\mathrm{VI})$ to $\mathrm{U}(\mathrm{IV})$ produces mixtures of nanoparticulate uraninite and noncrystalline U(IV) species associated with bacterial biomass (e.g., Senko et al., 2007; Bernier-Latmani et al., 2010; Boyanov et al., 2011). The presence and relative abundances of U(VI), $\mathrm{UO}_{2(\mathrm{~s})}$, and noncrystalline U(IV) species are typically estimated using $\mathrm{U} \mathrm{L}_{\mathrm{III}}$-edge EXAFS data. The presence of a $\mathrm{U}-\mathrm{U}$ pair correlation in these data at $3.85 \AA$ is indicative (in our system) of the presence of uraninite (O'Loughlin et al., 2003; Schofield et al., 2008; Boyanov et al., 2011). In XAS spectra obtained from laboratory pure cultures (Bernier-Latmani et al., 2010) and natural sediments biostimulated with an electron donor (Sharp et al., 2011), there is permissive evidence that noncrystalline U(IV) is at least in part associated with phosphate groups on microbial biomass. There is also evidence that the presence of inorganic phosphate in the aqueous medium during microbial U(VI) reduction significantly increases the fraction of noncrystalline U(IV) produced (Bernier-Latmani et al., 2010; Boyanov et al., 2011). Boyanov et al. (2011) tested the reduction of carbonate-complexed U(VI) by a variety of Gram-positive and Gram-negative bacteria in the presence and absence of solution phosphate $\left(290 \mu \mathrm{M}\right.$ as $\left.\mathrm{KH}_{2} \mathrm{PO}_{4}\right)$. The authors found that, regardless of bacterial species, a noncrystalline U(IV)-phosphate species associated with the solid phase was formed in the presence of solution phosphate. In the absence of phosphate, nano-uraninite was produced by Shewanella oneidensis MR-1 and Anaeromyxobacter dehalogenans 2CP-C, while a mixture of nanoparticulate uraninite and U(IV)-carbonate complexes was formed by Desulfitobacterium spp. A recent systematic study of the influence of solution chemistry on the nature of $\mathrm{U}(\mathrm{VI})$ reduction products shows that the presence of orthophosphate in the medium is not a prerequisite for noncrystalline U(IV) formation, thus indirectly suggesting that phosphate presumed to bind U(IV) may be of biological origin (Stylo et al., 2013). Previous results indicate that the formation of noncrystalline U(IV) versus uraninite depended strongly on the chemical environment in which $S$. oneidensis was carrying out $\mathrm{U}(\mathrm{VI})$ reduction (BernierLatmani et al., 2010). Hence, it is possible to modulate the formation of uraninite versus noncrystalline U(IV) based on solution composition.

Shell-by shell fitting of $\mathrm{U}_{\mathrm{III}^{-}}$-edge EXAFS data has suggested the association of noncrystalline U(IV) with phosphoryl moieties on biomass or mineral surfaces (e.g., Senko et al., 2007; Bernier-Latmani et al., 2010; Chakraborty et al., 2010; Veeramani et al., 2011). However, the inability to unambiguously distinguish between U-P and U-C coordination pairs in the fitting and the potential speciation complexity (i.e., the presence of several species) of what is referred to as noncrystalline U(IV) call for a more rigorous evaluation of this species. Bargar et al. (2013) recently proposed that noncrystalline U(IV) species found in biostimulated sediments may be comprised of a spectrum of species ranging from true monomers to phosphate coordination polymers to which $\mathrm{U}(\mathrm{IV})$ is bound. To our knowledge no experimental evidence of these U(IV)-P associations in biomass is extant outside of inferences from EXAFS fits (see above). Crucially, the degree of polymerization of phosphate, if any, cannot be determined using U EXAFS. To address these questions, it is necessary to use spectroscopic techniques such as FTIR or P XAS that directly probe the coordination environment around phosphate. Premised on these studies and the hypothesis that a large fraction of noncrystalline $\mathrm{U}(\mathrm{IV})$ is bound to microbial phosphate functional groups, we investigated the coordination environment of noncrystalline U(IV) species associated with $S$. oneidensis MR-1 bacterial cells. To provide a holistic structural picture of the U(IV) complexes, we used techniques capable of directly characterizing the local structure of both the functional groups (FTIR and P XAS) and U(IV) (U $\mathrm{L}_{\mathrm{III}}^{-}$ edge EXAFS). Anoxic cultures containing biogenic uraninite, noncrystalline U(IV), or no uranium were produced as a function of $\mathrm{pH}$ and compared to standard materials using four complementary techniques. $\mathrm{U} \mathrm{L}_{\mathrm{III}}$ edge EXAFS and a bicarbonate chemical extraction method (Alessi et al., 2012) were used to verify the reduction of U(VI) and the production of noncrystalline U(IV) or biogenic uraninite. Phosphorus K-edge XAS analyses provided unambiguous evidence that noncrystalline U(IV) species are associated with organic $\mathrm{P}$ functional groups. Infrared spectroscopy (IR) allowed for more in-depth probing of the types of functional groups with which noncrystalline $\mathrm{U}(\mathrm{IV})$ is associated. Shell-by-shell fitting of the U EXAFS, constrained by the FTIR and P XAS results, offer further glimpses into the nature of U(IV) coordination. Our results show conclusively for the first time that noncrystalline $\mathrm{U}(\mathrm{IV})$ is coordinated to biomass phosphorus functional groups, as inorganic U(IV) phosphate species, and likely in the framework of phosphate coordination polymers. 


\section{MATERIALS AND METHODS}

\subsection{Media and cultures}

S. oneidensis MR-1 was cultured, grown in Luria Bertani (LB) medium, and processed as described previously (Bernier-Latmani et al., 2010). All reagents used in the study were of analytical grade or higher, and ultrapure water (resistivity $18.2 \mathrm{M} \Omega \mathrm{cm}$ ) was used in preparing all solutions. All components of the growth media were sterilized by autoclaving prior to use.

\subsection{Uranium reduction}

Bacterial uranium reduction experiments were conducted in an anoxic chamber (Coy Laboratory Products, Grass Lake, Michigan) containing 2-3\% $\mathrm{H}_{2}$ and a balance of $\mathrm{N}_{2}$. After the cells were grown aerobically in LB medium, they were washed once in an anoxic solution containing $30 \mathrm{mM} \mathrm{NaHCO}$ and $20 \mathrm{mM}$ PIPES buffer set to $\mathrm{pH} 6.8$, hereafter called BP medium. In order to favor the formation of nanoparticulate uraninite, cells were suspended in BP medium to an optical density $\left(\mathrm{OD}_{600}\right)$ of 1.0 , and the system amended with $1 \mathrm{mM}$ uranyl acetate and $20 \mathrm{mM}$ L(+)-lactic acid (Bernier-Latmani et al., 2010). To favor the formation of noncrystalline U(IV) species, the same components were suspended in Widdel low phosphate (WLP) medium, the composition of which is listed in Supplementary Information Table 1 . WLP contains $220 \mu \mathrm{M}$ phosphate from potassium dihydrogen phosphate $\left(\mathrm{KH}_{2}\right.$ $\left.\mathrm{PO}_{4}\right)$. The $\mathrm{pH}$ of either experiment was adjusted to target values ( $\mathrm{pH} 5.5-8.5$ in one $\mathrm{pH}$ unit increments) by adding small volumes of concentrated $\mathrm{NaOH}$ and $\mathrm{HCl}$ immediately following the addition of bacterial cells and electron donor to the reduction media, but prior to the addition of uranyl acetate. $\mathrm{pH}$ measurements were conducted in an anaerobic chamber containing $3 \% \mathrm{H}_{2}$ and $97 \% \mathrm{~N}_{2}$, and measured continuously for $5 \mathrm{~min}$ until the $\mathrm{pH}$ value measured was constant to within $\pm 0.01 \mathrm{pH}$ units. Although reduction of $\mathrm{U}(\mathrm{VI})$ in the two media results in systems that consist largely of either biogenic uraninite or noncrystalline $\mathrm{U}(\mathrm{IV})$, the systems are not pure end members, and in fact contain mixtures of both biogenic nano-uraninite and noncrystalline U(IV) (Alessi et al., 2012).

Chemogenic U(IV)-phosphate precipitates were produced by dissolving $181 \mathrm{mg}$ of biogenic uraninite nanoparticles in a $40 \mathrm{ml}$ solution of anoxic $6 \mathrm{M} \mathrm{HCl}$, resulting in a solution containing $16.8 \mathrm{mM}$ U(IV). The absence of U(VI) in the solution was verified using a Kinetic Phosphorescence Analyzer (KPA; Chemchek Instruments Inc., Richland, Washington). The biogenic nanoparticles were produced as described in the prior paragraph, and isolated from the biomass according to the method in Schofield et al. (2008) before being dissolved. The U(IV) solution was passed through a $0.2 \mu \mathrm{m}$ PTFE filter, and $\mathrm{Na}_{3} \mathrm{PO}_{4}$ was added to two $8 \mathrm{ml}$ aliquots of the solution to a final concentration of $100 \mathrm{mM}$. After the phosphate addition, $\mathrm{NaOH}$ was added to each aliquot to achieve final $\mathrm{pH}$ values of 5.5 and 8.5. The resulting precipitates were placed in sealed Teflon ${ }^{\circledR}$-coated tubes, centrifuged at $10,000 \mathrm{~g}$ for
$10 \mathrm{~min}$, and the majority of the supernatant discarded. The precipitates were kept in $\sim 1 \mathrm{ml}$ of supernatant inside of gas-tight sealed serum bottles filled with $\mathrm{N}_{2}(\mathrm{~g})$ during shipping for U EXAFS and IR analyses.

\subsection{X-ray absorption spectroscopy}

Uranium $\mathrm{L}_{\mathrm{III}}$-edge (17.2 keV) X-ray absorption spectra were measured at beamline 4-1 of the Stanford Synchrotron Radiation Lightsource (SSRL). Samples were placed in glass serum bottles with butyl stoppers and aluminum crimp seals. The serum bottles were shipped to SSRL in a gas-tight sealed stainless steel canister (Schuett-biotec $\mathrm{GmbH}$, Göttingen, Germany) filled with $\mathrm{N}_{2}$ to a slightly positive pressure. Upon arrival the samples were centrifuged to wet biomass pellets and mounted in aluminum holders with Kapton ${ }^{\circledR}$ windows inside an anoxic chamber containing $2-5 \% \mathrm{H}_{2}$ with a balance of $\mathrm{N}_{2}$. The aluminum sample holders were screwed to a fixture, mounted in a liquid nitrogen cryostat and cooled to $77 \mathrm{~K}$. The space surrounding the sample holder portion of this assembly was evacuated during XAS analyses, preventing oxygen exposure. The vacuum chamber is fitted with Kapton ${ }^{\circledR}$ windows to allow for X-ray energy to pass to the samples and out to the fluorescence detector or secondary ion chambers. Data were collected using both transmission and fluorescence detectors. A double-crystal Si (220) monochromator, detuned $30 \%$ to reduce harmonics affecting the primary beam, was used to reject higher harmonic intensities, and beam line energy resolution was controlled at much less than the $\mathrm{U}_{\mathrm{III}}$-edge intrinsic line width by adjusting vertical slits upstream of the monochromator. EXAFS data were normalized, background subtracted, and analyzed using the SixPACK (Webb, 2005) and Horae (Ravel and Newville, 2005) program packages. Backscattering phase and amplitude functions used to fit the spectra were taken from FEFF8 (Rehr et al., 1992). Linear combination fitting of spectra was performed in $k^{3}$-weighted $k$-space between $k=3$ and 10.2, using three end-members: uranyl acetate as a U(VI) reference, noncrystalline U(IV) associated with biomass, and biogenic uraninite associated with biomass. In the case of the biogenic uraninite sample, the noncrystalline $\mathrm{U}(\mathrm{IV})$ fraction of the total $\mathrm{U}$ (always present in biological U(VI) reductions) was removed by bicarbonate extraction (Alessi et al., 2012), and the resulting solids were washed with anoxic water and pelleted for EXAFS analysis.

Phosphorus K-edge $(2.1 \mathrm{keV})$ XAS measurements were conducted at the PHOENIX beamline of the Swiss Light Source (SLS). Samples were centrifuged and the resulting bacterial pellets dried to powders under a $\mathrm{N}_{2}$ atmosphere. The dried samples were placed in serum bottles with butyl stoppers, and transported to SLS in a stainless steel shipping canister as described previously. Powders were mounted for XAS analysis by pressing them into a small strip of indium metal foil on a copper sample holder inside an anoxic sample chamber filled with $\mathrm{N}_{2}$. Immediately prior to analysis, mounted samples were transferred from anoxic canisters to the XAS sample chamber. The chamber was promptly evacuated to a pressure of a few $10^{-5}$ mbar, and XAS data was collected by recording the intensity of 
the $\mathrm{K} \alpha$ fluorescence of the phosphorus with a silicon drift detector as a function of the beam energy. Two plane parallel mirrors were used to suppress any higher harmonics contribution from the undulator source. The energy was selected with a double crystal monochromator using Si (1 111$)$ crystals. The energy resolution was approximately $0.6 \mathrm{eV}$ at the $\mathrm{P}$ K-edge. X-ray absorption near edge structure (XANES) data were background subtracted and normalized with a 3 rd order polynomial in the post-edge region.

\subsection{Infrared (IR) spectroscopy}

IR spectroscopy was conducted using a VERTEX 80v FTIR spectrometer (Bruker Optik GmbH, Ettlingen, Germany) equipped with a single crystal zinc selenide attenuated total reflectance (ATR) accessory (Harrick Scientific) and operated in a room maintained at $25 \pm 0.2{ }^{\circ} \mathrm{C}$. Prior to mounting a sample, the ATR accessory was placed in a glove bag containing an $\mathrm{N}_{2}$ atmosphere for 30 min to remove oxygen from the crystal surface. Bacterial suspensions containing $\mathrm{U}(\mathrm{IV})$ were centrifuged in sealed tubes containing a headspace of $\mathrm{N}_{2(\mathrm{~g})}$ at $5000 \mathrm{~g}$ for $20 \mathrm{~min}$. Aliquots of the resulting supernatants were pipetted onto the crystal surface and analyzed to quantify aqueous organic species present in solution. Wet bacterial pellets were mounted by spreading them directly on the ATR crystal. A plastic cup with a rubber seal was fastened over the crystal and sample prior to removal from the anoxic glove bag, the ATR assembly placed inside the spectrometer, and immediately evacuated to a pressure of less than 5 mbar. 500 scans with a $4 \mathrm{~cm}^{-1}$ resolution were collected between 550 and $7500 \mathrm{~cm}^{-1}$, and averaged for each analysis. The ATR crystal was cleaned with methanol and distilled water between analyses. To isolate the bacterial cell signal and to remove contributions from bulk water and ions in solution, the supernatant spectrum was subtracted from the corresponding bacterial paste spectrum. The critical step was to remove the water peak originating from the bending mode of bulk water. The subtraction was achieved by matching the sharply increased background between 800 and $1000 \mathrm{~cm}^{-1}$, caused by water libration modes, and ensuring that no negative absorbance values were obtained in the region around the strong water bending mode at $1638 \mathrm{~cm}^{-1}$; the subtraction factor varied between 0.99 and 1.0. Finally, the difference spectra were normalized to the same total area in the region 800$1800 \mathrm{~cm}^{-1}$ in order to correct for differences in the amount of cells on the ATR crystal. Data were processed using the Bruker OPUS spectroscopy software package.

\subsection{Chemical extraction of uranium species}

Noncrystalline U(IV), uraninite, and traces of adsorbed $\mathrm{U}(\mathrm{VI})$ associated with bacterial cells following microbial uranium reduction were quantified by extraction with $1 \mathrm{M}$ bicarbonate (Alessi et al., 2012). The method selectively releases solids-associated noncrystalline U(IV) and adsorbed $\mathrm{U}(\mathrm{VI})$ into solution while leaving uraninite associated with the extracted solids. Extracted U(VI) and noncrystalline U(IV) are differentiated in solution through the use of a KPA.

\section{RESULTS AND DISCUSSION}

\subsection{Uranium reduction products, and their quantification with bicarbonate extraction}

To identify the conditions under which disordered noncrystalline U(IV) species, and nanoparticulate uraninite are formed by microbial reduction, U(VI) reduction was conducted in two chemical media - WLP or BP - to favor the formation of biomass-associated noncrystalline U(IV) species or uraninite, respectively. Notably, U(VI) reduction in either of these reduction media does not lead to the production of samples containing either $100 \%$ uraninite or $100 \%$ noncrystalline U(IV). The contribution of noncrystalline U(IV) and uraninite to total $U$ in each system was assessed by applying a bicarbonate extraction method selective for noncrystalline U(IV) species (Alessi et al., 2012). Generally, the systems favoring the production of noncrystalline $\mathrm{U}(\mathrm{IV})$ contained $\geqslant 70 \%$ noncrystalline $\mathrm{U}(\mathrm{IV})$, with those at a higher uranium loading $(1000 \mu \mathrm{M})$ having a slightly higher fraction of uraninite than those with less $\mathrm{U}(400 \mu \mathrm{M})$ at a given reduction $\mathrm{pH}$ (Table 1).

In the systems favoring uraninite production (BP medium), those at circumneutral $\mathrm{pH}$ values ( $\mathrm{pH} 6.5$ or 7.5 ) were found to contain approximately $80 \%$ uraninite. Of note, the extractions indicate that the $\mathrm{pH} 5.5$ system produced only $\sim 48 \%$ biogenic uraninite, and only a small fraction of $\mathrm{U}(\mathrm{VI})(9.1 \%, 91 \mu \mathrm{M})$ was reduced in the $\mathrm{pH} 8.5$ system. In this latter system, the unreduced U(VI) fraction remained in the reduction medium containing bicarbonate, and was largely removed when the medium was decanted following sample centrifugation to collect the microbial pellet. Thus, the resulting pelleted sample contained only $9.1 \%$ of the initial $1000 \mu \mathrm{M}$ uranium added, and the majority of this uranium was as U(IV). The extraction results are described in light of the U EXAFS results in Section 3.4.

\subsection{Phosphorus K-edge XANES}

Because $\mathrm{U}_{\mathrm{III}}$ edge EXAFS data have suggested but not conclusively shown that noncrystalline U(IV) is associated with microbial phosphoryl moieties (e.g., Bernier-Latmani et al., 2010; Boyanov et al., 2011), P K-edge XAS spectroscopy was conducted. Analyses were performed on $S$. oneidensis strain MR-1 cells with noncrystalline U(IV) $(400 \mu \mathrm{M})$, cells without uranium, and a chemogenic U(IV)-phosphate precipitate. Fig. 1A displays the P K-edge spectra. The post-edge area is illustrated in Fig. 1B. Pre-edge peaks, the edge position, and post-edge features in $\mathrm{P}$ XANES data can be used to probe phosphate speciation in environmental samples (George, 1993; Toor et al., 2006). Organic $\mathrm{P}$ species such as those associated with biomass often exhibit one broad post-edge peak centered between 2167 and $2170 \mathrm{eV}$, depending on the compound (Brandes et al., 2007; Hesterberg, 2010). For example, the post-edge peak for ATP (adenosine 5'-triphosphate) is centered at $2170 \mathrm{eV}$, whereas O-phosphoryl ethanolamine, found in lipopolysaccharides (Yeh et al., 1992), exhibits a peak centered at $2167 \mathrm{eV}$. Our cells-only experiments exhibit one broad peak centered at $2168 \mathrm{eV}$ (Fig. 1B), consistent with 
Table 1

Results of bicarbonate extractions and U EXAFS linear combination fits (LCF) to quantify \% noncrystalline U(IV) and \% uraninite in experimental systems. Reductions were conducted to favor the formation of biogenic uraninite (BP medium) or noncrystalline U(IV) species (WLP medium). Error ranges for the bicarbonate extraction method include the combined replicate and instrumental error, and errors for LCF fitting are generally accepted to be within $10 \%$.

\begin{tabular}{|c|c|c|c|c|c|c|c|}
\hline \multirow[t]{2}{*}{ System } & \multirow[t]{2}{*}{ EXAFS spectrum } & \multicolumn{2}{|l|}{$\mathrm{pH}$} & \multicolumn{2}{|c|}{ Bicarbonate extraction results } & \multicolumn{2}{|c|}{ EXAFS linear combination fits } \\
\hline & & Initial & Final & $\%$ noncrystalline U(IV) & $\%$ uraninite & $\%$ noncrystalline U(IV) & $\%$ uraninite \\
\hline \multirow[t]{4}{*}{$1000 \mu \mathrm{M}$ BP medium } & $\mathrm{E}$ & 5.5 & 7.3 & $52.4 \pm 3.3$ & 47.6 & 47.3 & 52.7 \\
\hline & $\mathrm{F}$ & 6.5 & 7.8 & $20.7 \pm 1.3$ & 79.3 & 26.3 & 73.7 \\
\hline & G & 7.5 & 8.6 & $20.6 \pm 1.3$ & 79.4 & 47.3 & 52.7 \\
\hline & $\mathrm{H}$ & $8.5^{\mathrm{a}}$ & 8.9 & $12.5 \pm 0.8$ & 87.5 & 57.6 & 42.4 \\
\hline \multirow[t]{4}{*}{$1000 \mu \mathrm{M}$ WLP medium } & A & 5.5 & 5.7 & $82.9 \pm 7.0$ & 17.1 & 90.3 & 9.7 \\
\hline & B & 6.5 & 6.6 & $88.9 \pm 7.6$ & 11.1 & 96.6 & 3.4 \\
\hline & $\mathrm{C}$ & 7.5 & 7.2 & $72.3 \pm 3.8$ & 27.7 & 84 & 16 \\
\hline & $\mathrm{D}$ & 8.5 & 7.9 & $81.1 \pm 3.8$ & 18.9 & 92.4 & 7.6 \\
\hline \multirow[t]{4}{*}{$400 \mu \mathrm{M}$ WLP medium } & - & 5.5 & 5.5 & $87.2 \pm 5.3$ & 12.8 & - & - \\
\hline & - & 6.5 & 6.3 & $92.4 \pm 0.9$ & 7.6 & - & - \\
\hline & - & 7.5 & 7.0 & $81.6 \pm 2.2$ & 18.4 & - & - \\
\hline & - & 8.5 & 7.8 & $99.5 \pm 12.1$ & 0.5 & - & - \\
\hline
\end{tabular}

${ }^{\text {a }}$ Note that for the $\mathrm{pH} 8.5,1000 \mu \mathrm{M}$ uraninite sample, only $9.1 \%$ of the total U (i.e., $91 \mu \mathrm{M}$ ) was reduced, however the majority of the remaining $\mathrm{U}(\mathrm{VI})$ fraction was removed when the reduction supernatant was decanted to collect the microbial pellet. The percents reported in the table refer to the largely reduced $U$ remaining in this sample.
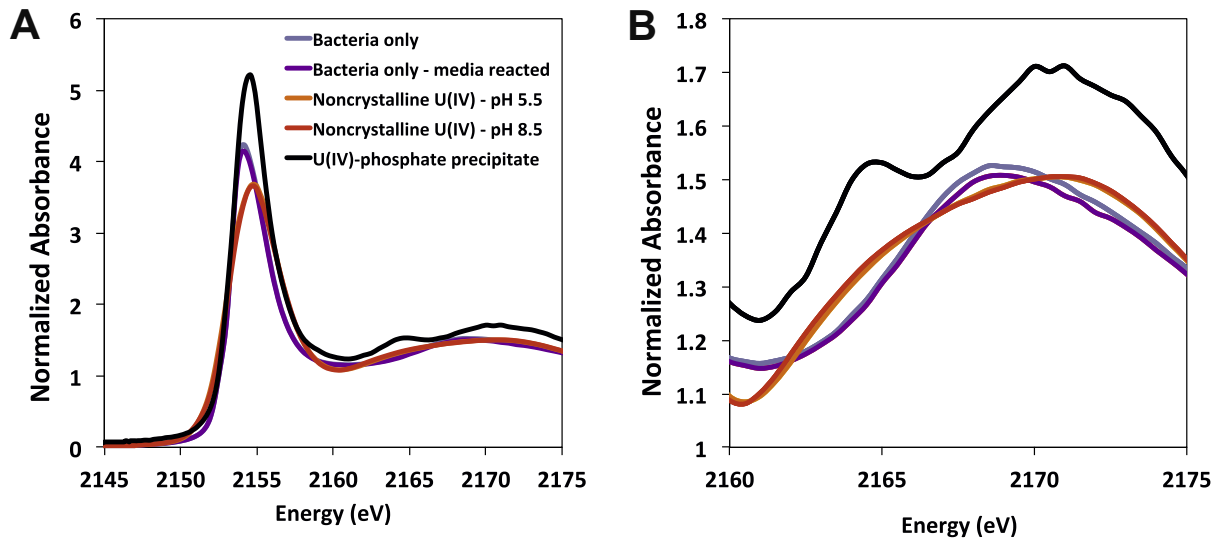

Fig. 1. Phosphorus K-edge energy data comparing systems containing $S$. oneidensis MR-1 bacteria, the same bacteria with noncrystalline $\mathrm{U}(\mathrm{IV})(400 \mu \mathrm{M})$, and a chemogenic U(IV)-phosphate precipitate (A). Panel B illustrates the post-edge area (the region $2160-2175 \mathrm{eV}$ ) in the left panel.

a mixture of several types of phosphorus-bearing organic molecules found in bacteria.

When phosphate is coordinated with a metal, features in the post-edge region may appear (Ingall et al., 2011). These absorption resonances occur at higher energy than that of the ionization energy $\left(E_{0}\right)$ of core $(1 s)$ electrons in $\mathrm{P}$, and are strongly controlled by internuclear distances, even in condensed but non-crystalline systems comprised of $\mathrm{P}_{x} \mathrm{O}_{y}$ chains (Franke and Hormes, 1995). The spectra of our chemogenic U(IV) phosphate solid, found to be amorphous by Xray diffraction (XRD) analysis (data not shown), exhibit two primary post-edge resonance peaks at 2165 and $2170 \mathrm{eV}$ (Fig. 1B), similar to other metal-coordinated phosphates. When noncrystalline U(IV) is present in the bacterial system, there is a significant shift in the shape of the energy curve from the cells-only system towards that of the chemogenic U(IV)-phosphate precipitate. In particular, a concave shape more closely resembling the U(IV)-phosphate spectrum replaces the convex shape of the resonance features past the edge at energies between 2160 and $2175 \mathrm{eV}$. Notably, there is little difference between the noncrystalline U(IV) samples produced at $\mathrm{pH} 5.5$ and 8.5, consistent with the U EXAFS and infrared spectroscopy results (see below). In order to ensure the differences in the cells-only and noncrystalline U(IV) systems were due to the addition of $U$ and not other components found in the WLP reduction medium (Supplementary Information Table 1), we reacted $S$. oneidensis cells with WLP medium (without $\mathrm{U}$ ) and compared the results to those from cells not reacted with WLP. Essentially no differences in spectral shape emerge (Supplementary Information 
Fig. 1), indicating that the changes we observe are due solely to the presence of $\mathrm{U}$.

Linear combination fitting, using the bacteria-only and U(IV)-phosphate precipitates as end-members, suggests that the noncrystalline U(IV) samples contain approximately $50 \%$ of each end-member at both $\mathrm{pH} 5.5$ and 8.5 (Fig. 2). This result suggests that a significant fraction of the biomass phosphate groups are associated with U(IV). The phosphorus XAS provide direct experimental evidence that the noncrystalline U(IV) species associated with bacterial cells is a phosphate-bound species.

\subsection{Infrared spectroscopy of U(IV) species}

IR spectroscopy can be used to probe changes in the absorption bands of specific functional groups at the bacterial surface under various experimental conditions. Here, we aim at determining whether the presence of biogenic uraninite and/or noncrystalline U(IV) species perturbs the infrared spectrum, and if so, in which absorption bands. Changes in the intensity and position of the absorption band of a particular functional group that correlate with the presence of $U$ are taken to imply chemical bonding of the U(IV) species with the corresponding group(s).

IR spectra were collected on U-free $S$. oneidensis MR-1 bacterial cells adjusted to $\mathrm{pH} \mathrm{3-9}$ in $50 \mathrm{mM} \mathrm{NaCl}$ solutions (Fig. 3) to provide a baseline to compare to the uraniumcontaining systems. By comparing the IR spectra from known standard compounds to those obtained from Gram-negative and Gram-positive bacteria, Jiang et al. (2004) established a series of absorption bands corresponding to specific bacterial surface functional groups, and Wang et al. (2010) determined IR bands associated with S. oneidensis MR-1 cells during different growth phases. We observe a similar series of absorption bands, which

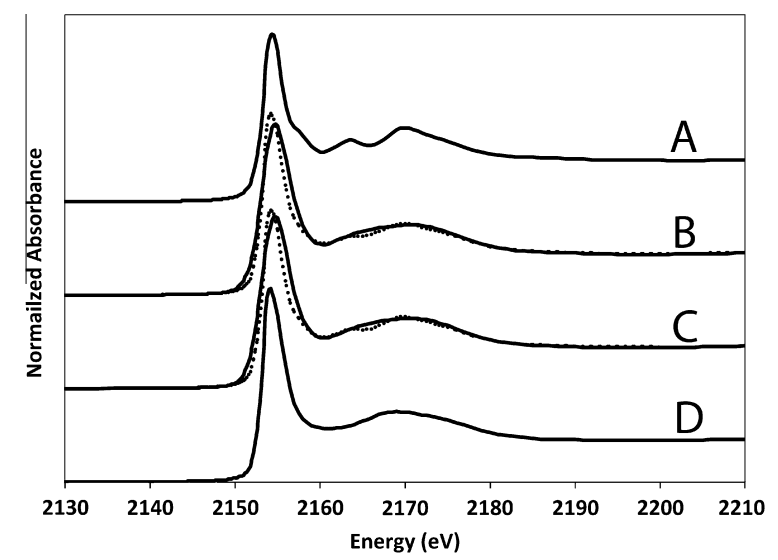

Fig. 2. Phosphorus K-edge XAS linear combination fitting (LCF) results for biomass noncrystalline $\mathrm{U}(\mathrm{IV})$ samples at (B) $\mathrm{pH} 8.5$ and (C) $\mathrm{pH}$ 5.5. End members used for fitting include (A) a chemogenic U(IV)-phosphate, and (D) $S$. oneidensis MR-1 cells treated with WLP medium (see Supplementary Information Table 1). The LCF (dashed lines) calculates that the $\mathrm{pH} 8.5$ system (B) can be modeled using $44 \%$ of spectrum A and $56 \%$ of spectrum $\mathrm{D}$, while the $\mathrm{pH} 5.5$ system (C) is comprised of $54 \%$ of spectrum A and $46 \%$ of spectrum D. are labeled in Fig. 3. Systematic spectral changes occur as a function of $\mathrm{pH}$ (marked with arrows in Fig. 3), and these changes can be ascribed exclusively to the protonation and deprotonation of carboxylic acid groups. At low $\mathrm{pH}$ the presence of protonated carboxyls are indicated by vibrations of $\mathrm{COOH}$ and $\mathrm{C}=\mathrm{O}$ at 1224 and $1720 \mathrm{~cm}^{-1}$, respectively. Increasing $\mathrm{pH}$ results in the appearance of a new band at $1398 \mathrm{~cm}^{-1}$ and concomitant decrease of the signals from the protonated carboxyls. The new band originates from a symmetric stretching vibration of the deprotonated carboxylic group (Jiang et al., 2004; Leone et al., 2007). The increase in $\mathrm{pH}$ is also accompanied by a change in the relative intensities of the amide I and II bands (Fig. 3). Most likely this is not caused by changes of the amide bonds (in cell proteins) but is a consequence of deprotonation of the carboxyls and the overlap with the asymmetric carboxyl stretching vibration that typically occurs in the same frequency region (around $1550 \mathrm{~cm}^{-1}$ ) as amide II (Leone et al., 2007). The correlation between the observed spectral changes and the protonation/deprotonation of carboxylic groups is further corroborated by a principle component analysis (PCA) of the spectra in Fig. 3 and subsequent modeling assuming one $\mathrm{pKa}$ (see Supplementary Information Fig. 2). The good match between this model and the experimental data indicates that only one type of infrared active functional group displays acid-base behavior in the $\mathrm{pH}$ range 3-9, and the obtained $\mathrm{pKa}$ value of 4.6 is also in agreement with protonation/deprotonation of carboxylic groups. Accordingly, and of particular interest in this study, only modest change is observed with $\mathrm{pH}$ in the phosphate symmetric and asymmetric stretching bands between approximately 1000 and $1250 \mathrm{~cm}^{-1}$, an area in which we expect to observe changes if uranium is coordinating with phosphate on microbial biomass.

IR analyses focused on samples prepared at $\mathrm{pH} 6.5$ or 8.5 , where $>79 \%$ of the total uranium associated with the cells was present as the target U(IV) species (Table 1). IR spectra from these samples are shown in Fig. 4 and compared to the uranium-free spectra in Fig. 3. Generally, changes observed in the IR spectra due to the addition of uranium to the system are larger than those due to changes in $\mathrm{pH}$ (Fig. 4). In the frequency region analyzed, the IR spectra are "silent" to biogenic $\mathrm{UO}_{2}$, that is, $\mathrm{UO}_{2}$ has no infrared absorption bands. It has recently been shown that stoichiometric $\mathrm{UO}_{2}$ only displays increased IR absorption below $600 \mathrm{~cm}^{-1}$, whereas at higher oxygen content (and thus the presence of U(VI)), bands appear between 700 and $800 \mathrm{~cm}^{-1}$ (Kim et al., 2012). Thus, the spectral changes we reported above for the noncrystalline system must be due to the formation of non-uraninite U(IV) products. Accordingly, the samples containing predominantly biogenic $\mathrm{UO}_{2}$ are similar to the uranium-free samples in the region between approximately $950-1200 \mathrm{~cm}^{-1}$, i.e., no major bands shift or new bands are detected. The following discussion focuses on the noncrystalline U(IV) spectra; further information about IR spectra from the biogenic $\mathrm{UO}_{2}$-favoring systems is in the Supplementary Discussion section.

The greatest changes in the spectra of the noncrystalline U(IV) samples are observed as a strong increase in the relative intensity of the bands in the region between 


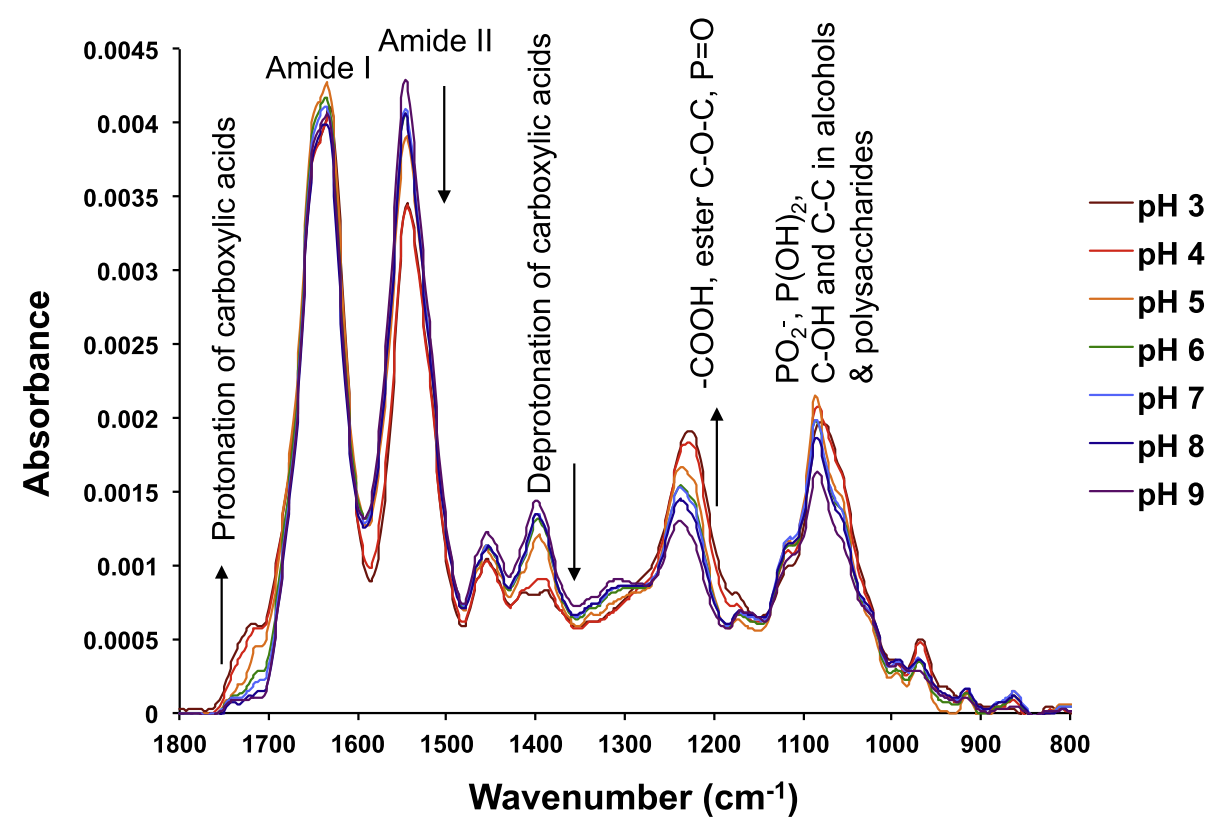

Fig. 3. FTIR spectra of uranium-free Shewanella oneidensis MR-1 biomass as a function of $\mathrm{pH}$ values between 3 and 9 . Arrows down indicate decreasing amplitude with decreasing $\mathrm{pH}$ and arrows up indicate increasing amplitude with decreasing $\mathrm{pH}$.

approximately 950 and $1200 \mathrm{~cm}^{-1}$ (i.e., the region containing the primary $\mathrm{P}-\mathrm{O}$ modes) as altered band positions and shapes in the same region, and in the suppression of a band at $\sim 1230 \mathrm{~cm}^{-1}$. These spectral changes suggest that U(IV) bonds to phosphate groups, either biomass phosphoryl groups such as those in lipopolysaccharides or phospholipids, or to form inorganic U(IV) phosphate precipitates.

A strong and broad peak is observed in the region centered at $1070 \mathrm{~cm}^{-1}$. In the presence of $U$, the apex of this band is shifted to significantly lower frequency with respect to the no-uranium control spectrum (Fig. 4A). This broad band is in good agreement with previously characterized U(IV) phosphate phases (Podor et al., 2003). Furthermore, the primary IR peak from a chemogenic U(IV) phosphate synthesized in this study aligns exactly with the peak in the $\mathrm{P}-\mathrm{O}$ region of the spectra from the $400 \mu \mathrm{M}$ noncrystalline $\mathrm{U}(\mathrm{IV})$-containing experiments at $\mathrm{pH} 6.5$ and 8.5 (Fig. 4A and B). This finding is consistent with the formation of U(IV) phosphate solids, however it may also be indicative of changes in protein concentration or increased production of extracellular polymeric substances (EPS) resulting as a bacterial toxicity response to the presence of U. Finally, the high similarity of the spectra at $\mathrm{pH} 6.5$ and 8.5 indicates that the same U(IV) phosphate species form irrespective of $\mathrm{pH}$. At higher U loadings $(1000 \mu \mathrm{M})$ under noncrystalline $\mathrm{U}(\mathrm{IV})$-producing conditions at $\mathrm{pH}$ 6.5 and 8.5 , the strong and broad band centered at $1070 \mathrm{~cm}^{-1}$ has a slightly different shape as compared to the lower loading (Fig. 4A and 4B). This implies that the local structure and polymerization of phosphate depends on the total uranium concentration.

The $\sim 1230 \mathrm{~cm}^{-1}$ band, attributed to phosphate diesters (Jiang et al., 2004; Wang et al., 2010) provides further information about the effect of $U$ addition to the cells. In all systems containing $U$, the intensity of the band is suppressed (Fig. 3) to a degree that cannot be explained by deprotonation effects (Fig. 4). This indicates that the phospholipids responsible for this band are destroyed by the addition of $U$ to the system, or that the association of U(IV) to phospholipids results in vibrational dampening at this frequency. The presence of reduced uranium also seems to affect the relative intensity of the amide I and amide II bands. The consistent effect in all samples containing noncrystalline U(IV) suggests that reduction causes a perturbation of the structure/composition of some proteins. The changes in the amide bands indicate that some of the $\mathrm{U}(\mathrm{IV})$ is coordinated directly to the biomass.

The overall speciation of uranium in noncrystalline U(IV) samples in the present study indicates significant contributions from U(IV) bonded to biomass phosphoryl groups. Phosphoryl sites are expected to be present on cell surfaces in lipopolysaccharides (Langley and Beveridge, 1999; Korenevsky et al., 2002). In addition, we expect EPS to have been produced during our incubations (Stylo et al., 2013). Recent studies show that EPS contains a mixture of phosphate-bearing organic molecules and polymers such as nucleic acids, proteins, lipids, and polysaccharides (Flemming et al., 2007; Flemming and Wingender, 2010; McCrate et al., 2013). Stylo et al. (2013) demonstrated that during uranium reduction, cells in medium containing some anions (e.g., phosphate, sulfate) produce more EPS than those in medium devoid of these solutes, likely because they are required for the cells to be in a viable physiological state. Transmission electron microscopy (TEM) analyses, conducted on microbial U(VI) reduction samples identical to those studied here, indicated a spatial correlation 

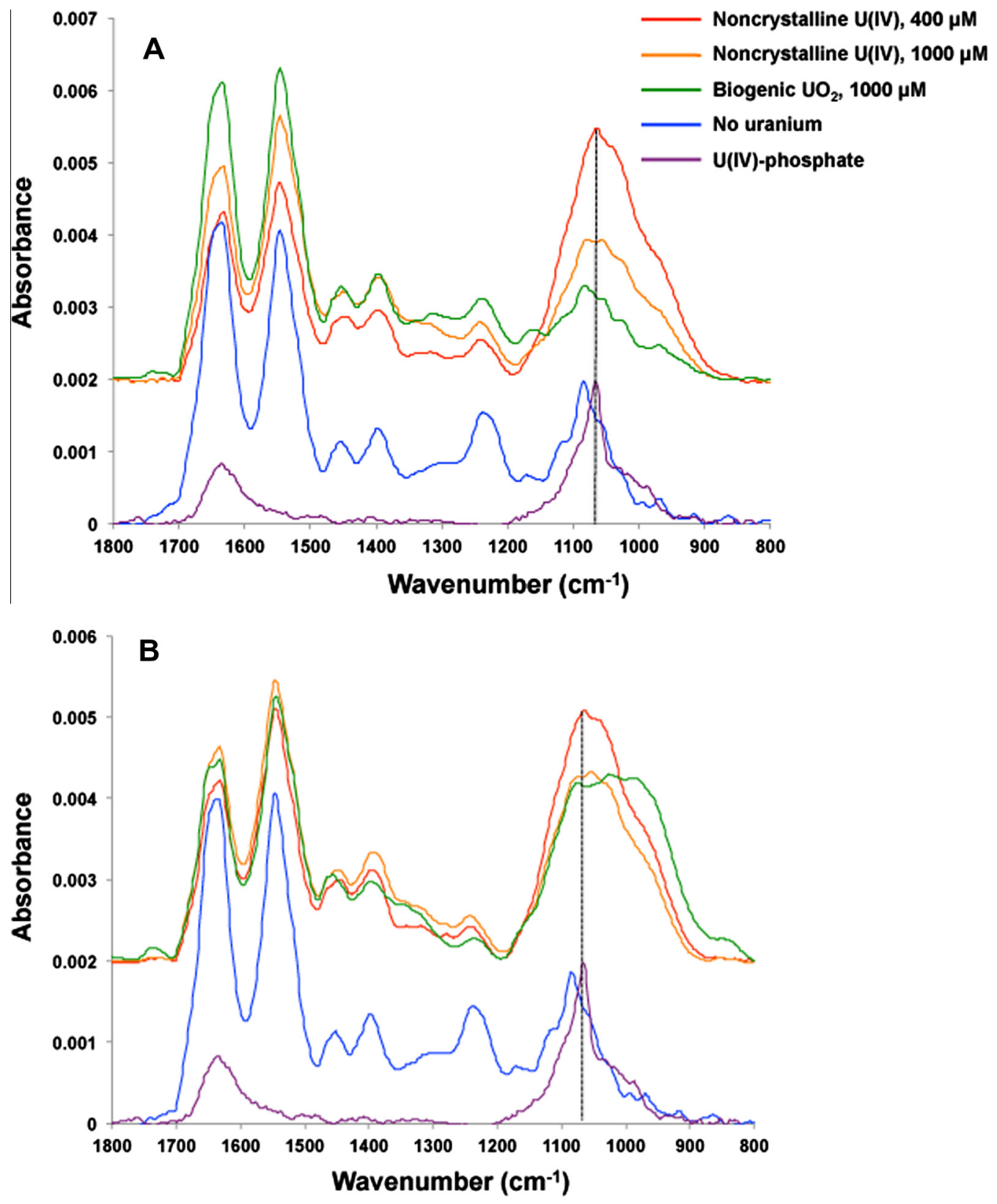

Fig. 4. Infrared spectroscopy data for uranium-containing experiments conducted at (A) $\mathrm{pH} 6.5$ and (B) $\mathrm{pH}$ 8.5. Dashed vertical lines indicate alignment of noncrystalline $\mathrm{U}(\mathrm{IV}) 400 \mu \mathrm{M}$ bands with the main spectral feature of the chemogenic U(IV)-phosphate, at a wavelength of approximately $1070 \mathrm{~cm}^{-1}$.

between extracellular $\mathrm{U}$ and $\mathrm{P}$ (Bernier-Latmani et al., 2010). Thus, the prevalence of U(IV)-phosphate associations may result from an increased production of EPS as a toxicity response to the presence of $U$ in the WLP reduction medium. Images of noncrystalline U(IV) showed primarily the association of $U$ with features of organic origin (tufts) and contributions from discrete U(IV)- and phosphate-containing phases such as ningyoite. Furthermore, scanning X-ray transmission microscopy (STXM) studies of noncrystalline U(IV) show a marked correlation between uranium and the presence of polysaccharides (Stylo et al., 2013). Our P XANES and IR microscopy findings here show conclusively for the first time that a significant fraction of $\mathrm{U}(\mathrm{IV})$ is bound directly to biomass phosphoryl groups.

\subsection{Uranium X-ray absorption spectroscopy}

$\mathrm{U}_{\mathrm{III}}$-edge X-ray absorption spectra was measured from the $1000 \mu \mathrm{M} \mathrm{U}$ experimental systems and a U(IV)-phosphate precipitate produced at $\mathrm{pH} 7.0$ (Table 1) to gather structural information about the products of microbial $\mathrm{U}$ reduction. Extended X-ray Absorption Fine Structure (EXAFS) data, and the corresponding Fourier transforms of 
the EXAFS are presented in Fig. 5 for the experimental systems containing $1000 \mu \mathrm{M} U$ favoring the production of noncrystalline $\mathrm{U}(\mathrm{IV})$ (spectra A-D) and uraninite (spectra $\mathrm{E}-\mathrm{H}$ ), and U(IV)-phosphate precipitate (spectra I, J). The amplitude of the $c a 3.8 \AA$ (uncorrected for phase shift) peak in the Fourier transforms of the biomass systems is an indication of the degree of $\mathrm{U}-\mathrm{U}$ polymerization in each system (O'Loughlin et al., 2003; Schofield et al., 2008; Boyanov et al., 2011). Thus, this amplitude can be used to estimate the relative contributions of ordered uraninite versus noncrystalline $\mathrm{U}(\mathrm{IV})$, which does not exhibit a $\mathrm{U}-\mathrm{U}$ pair correlation (Schofield et al., 2008; Alessi et al., 2012). No significant differences are observed in the EXAFS of the noncrystalline U(IV)-favoring systems (Fig. 5, spectra A-D) suggesting that the relative abundance of uraninite and noncrystalline $\mathrm{U}(\mathrm{IV})$ are similar regardless of $\mathrm{pH}$ values and that the local structure around U(IV) is invariant in the sample series. The abundance of noncrystalline U(IV) determined by linear combination fitting (LCF) of the U EXAFS in these samples corresponds well with the results of the bicarbonate extractions of the same samples (Table 1). This result suggests that the extent of noncrystalline U(IV)
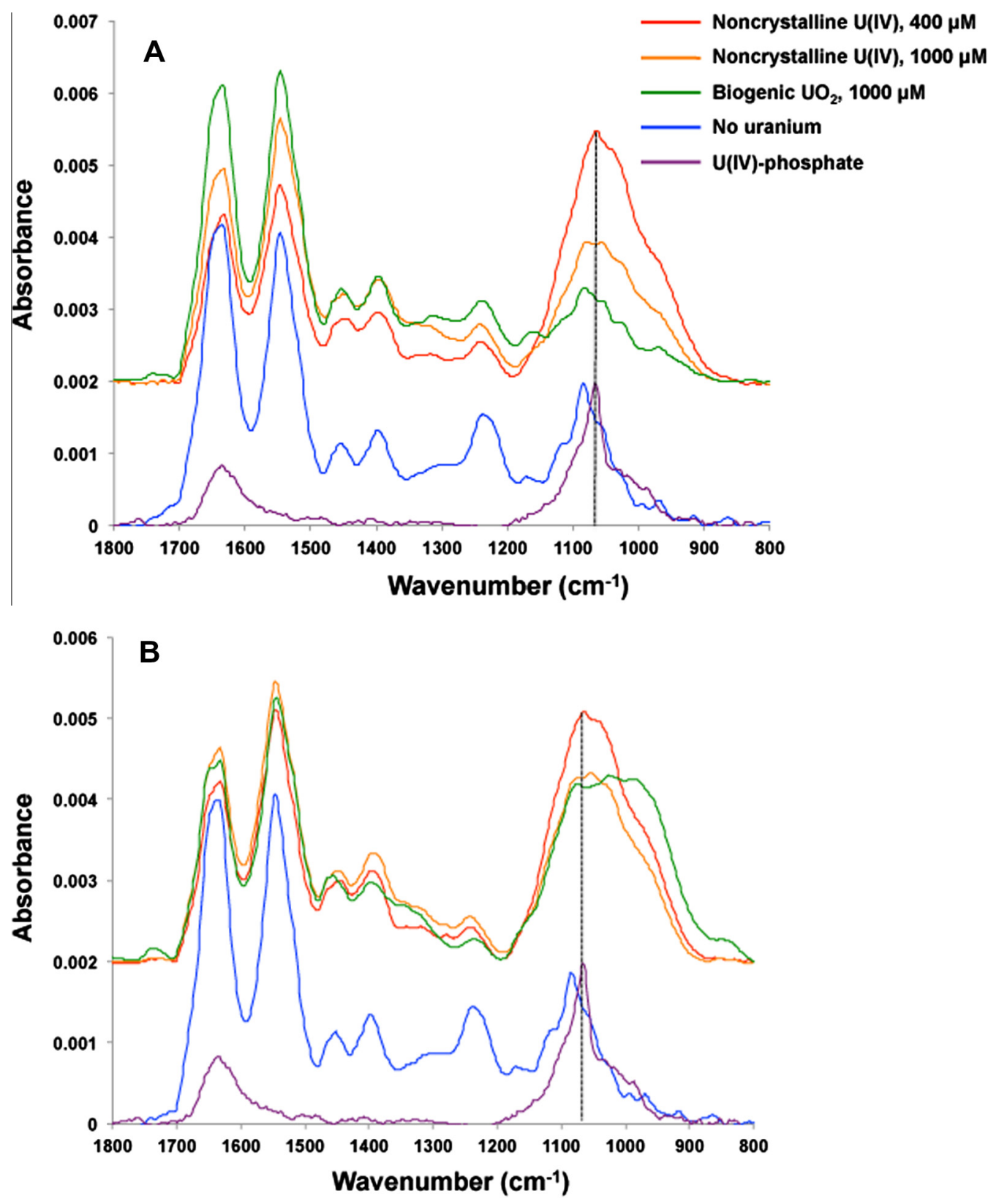

Fig. 5. Uranium $\mathrm{L}_{\mathrm{III}}$-edge EXAFS data (left panel) and Fourier transforms of the same data (right panel) for systems favoring noncrystalline $\mathrm{U}(\mathrm{IV})$ formation at $\mathrm{pH}$ 5.5-8.5 (A-D), biogenic uraninite at $\mathrm{pH} 5.5-8.5(\mathrm{E}-\mathrm{H})$, and chemogenic $\mathrm{U}(\mathrm{IV})$-phosphate precipitates produced at $\mathrm{pH}$ 5.5 (I) and 8.5 (J). Data for a U(IV)-phosphate precipitate produced at pH 7.0 is represented by spectrum I. Dashed lines indicate shell-byshell fits of each spectrum (see also Supplementary Information Tables 2-4). Fourier transforms were determined over the range $3<k<10.2$. 
formation and the local structure around noncrystalline $\mathrm{U}(\mathrm{IV})$ are not very sensitive to $\mathrm{pH}$ over the $\mathrm{pH}$ range tested here $(\mathrm{pH} 5.5-8.5)$ at a constant uranium loading. The same $\mathrm{pH}$ independence was observed for the IR spectra for $\mathrm{pH}$ 6.5 and 8.5 (Fig. 4). Based on the results of the IR and P $\mathrm{K}$-edge spectra, i.e., that indicated the coordination of noncrystalline U(IV) to phosphoryl moieties, shell-by-shell fits of the noncrystalline U(IV) EXAFS were performed. Average coordination numbers of $1.2 \pm 0.4,1.6 \pm 0.5$ and $3.0 \pm 0.2$ for the first $\mathrm{U}-\mathrm{P}(3.1 \AA)$, the second $\mathrm{U}-\mathrm{P}(3.7 \AA)$ and the U-U (3.8 $\AA$ ) shells were obtained (Supplementary Information Tables 2 and 3, and Supplementary Discussion). The U-P coordination numbers suggest that, on average, $\mathrm{U}(\mathrm{IV})$ is bound to at least one phosphate group in a bidentate conformation, and to one to two additional phosphate groups in a monodentate conformation. Thus, a significant fraction of the U(IV) coordination sphere is occupied by phosphate ligands. This conclusion is consistent with structures of inorganic U(IV) phosphates in which phosphate occurs as a polymerized network (i.e., as U(IV) coordination polymers). Finally, the U-U distance is consistent with biogenic uraninite nanoparticles (Bargar et al., 2008; Schofield et al., 2008).

Linear combination fits of the EXAFS spectra, using end-members described in Alessi et al. (2012), indicate that contributions from noncrystalline U(IV) represent $90 \%$, $97 \%, 84 \%$, and $92 \%$ of the total U(IV) in order of increasing equilibration $\mathrm{pH}$ value (Table 1 ). The bicarbonate extraction results for noncrystalline U(IV) in these samples are systematically lower, but within the approximately $10 \%$ error often cited for EXAFS linear combination fits (Kelly et al., 2008). However, there may be some fraction of noncrystalline U(IV) that is not bicarbonate labile, indicative of a spectrum of U(IV)-bearing products.

As discussed in Section 3.3, the infrared spectrum of the biogenic $\mathrm{UO}_{2}$-favoring system at $\mathrm{pH} 8.5$ (final $\mathrm{pH}$ 8.9) displays an unexpected increase in intensity and width between 900 and $1200 \mathrm{~cm}^{-1}$, which are attributable to traces of U(VI) due to incomplete $U$ reduction in this system. IR spectroscopy is highly sensitive to trace amounts of U(VI), manifested in the uranyl stretching modes centered around $920 \mathrm{~cm}^{-1}$ (Supplementary Information Fig. 3), whereas U XAS is far less sensitive to these traces. We do not expect uranyl sorption to the cells in this case (despite incomplete reduction) because the reduction medium contained $30 \mathrm{mM}$ bicarbonate, and U(VI) in the supernatant was removed after the centrifugation step used to collect the bacterial pellets for spectroscopic analyses. Additionally, a major difference between the EXAFS LCF and the bicarbonate extraction techniques for quantifying the amounts of uraninite and noncrystalline U(IV) is illustrated in the results for this sample. According to the bicarbonate extraction method, $88 \%$ of the total uranium pool was as uraninite, but the LCF indicates that only $58 \%$ is present as uraninite (Table 1). Similarly in the $\mathrm{pH} 7.5$ biogenic $\mathrm{UO}_{2}$-favoring system, where the final $\mathrm{pH}$ of the system after $\mathrm{U}(\mathrm{VI})$ reduction was 8.6 , the bicarbonate method suggests the sample contains approximately $79 \%$ uraninite, whereas the LCF indicates $53 \%$ (Table 1). We suggest that this divergence from expected behavior for IR, LCF and extraction data is attributable to the formation of a U-phosphate phase at higher $\mathrm{pH}$ that is more stable than U(IV) monomers, such as U(IV) within phosphate coordination polymers such as amorphous U(IV)-phosphate precipitates. This inference is based on prior similar U(VI) reduction experiments with S. oneidensis MR-1 cells (Bernier-Latmani et al., 2010), in which these precipitates were observed as electron-dense regions in TEM images, and determined to contain primarily $\mathrm{U}$ and $\mathrm{P}$ using energy dispersive X-ray spectroscopy (EDS). A fraction was identified to be ningyoite, $\mathrm{CaU}\left(\mathrm{PO}_{4}\right)_{2}$. Similar production of non-uraninite $\mathrm{U}(\mathrm{IV})$ precipitates, including ningyoite, was observed in the reduction of U(VI)-phosphate by Thermoterrabacterium ferrireducens (Khijniak et al., 2005), and by Bacillus subtilis (Rui et al., 2013). Because these precipitated phases are not extractable by the bicarbonate method and at the same time do not display a $\mathrm{U}-\mathrm{U}$ shell, the uraninite fraction is overestimated by bicarbonate extraction. The source of phosphorus in this case is likely to be cell lysis as the $\mathrm{pH}$ reached a value of 8.9 (Table 1). This observation underscores the importance of using multiple techniques to probe the system and constrain the speciation of the U(IV) products formed.

\subsection{Structural model for U(IV)-biopolymer complexes}

Bernier-Latmani et al. (2010) showed that noncrystalline U(IV) species were associated with hair-like structures ("tufts") on cell surfaces. Phosphoryl moieties associated with structures such as glucosamines in lipopolysaccharides located at the cell outer membrane could provide locations for the formation of U(IV) complexes. Numerous Shewanella spp. are known to contain lipopolysaccharides with phosphoryl-poor O-antigens that extend from the core polysaccharide at the cell membrane-solution interface (Korenevsky et al., 2002). S. oneidensis MR-1 is notable in that it lacks entirely the O-polysaccharides (Vinogradov et al., 2003), leaving the phosphoryl-rich core regions relatively exposed. Thus, binding of U(IV) to the phosphoryl groups in the diglucosamine diphosphate core of the lipopolysaccharide may be more facile in strain MR-1. The presence of phospholipid head groups at the cell membrane outer surface provides another source of biological phosphate to which U(IV) could bind. Additionally, binding to phosphate diesters in DNA or RNA is also likely due to the reported secretion of extracellular DNA (eDNA) by strain MR-1 cells exposed to U. eDNA could be associated with the extracellular polymeric matrix present in tight association with the cells (Cao et al., 2011). In our experiments, total $\mathrm{U}$ concentrations in the experiments were either 0.4 or $1.0 \mathrm{mM}$, so the coordination of U(IV) to several phosphate groups likely requires a cellular source of phosphate, separate from orthophosphate found in the WLP medium. The phosphate diester IR band is suppressed in systems containing U(IV) (Fig. 4), suggesting possible binding of U(IV) to DNA and/or phospholipids, providing a source of orthophosphate for the formation of polymers.

The formation of larger phosphate coordination polymers incorporating U(IV) requires a source of orthophosphate; possible sources include solution phosphate $(220 \mu \mathrm{M}$ in the WLP medium used here), orthophosphate released 

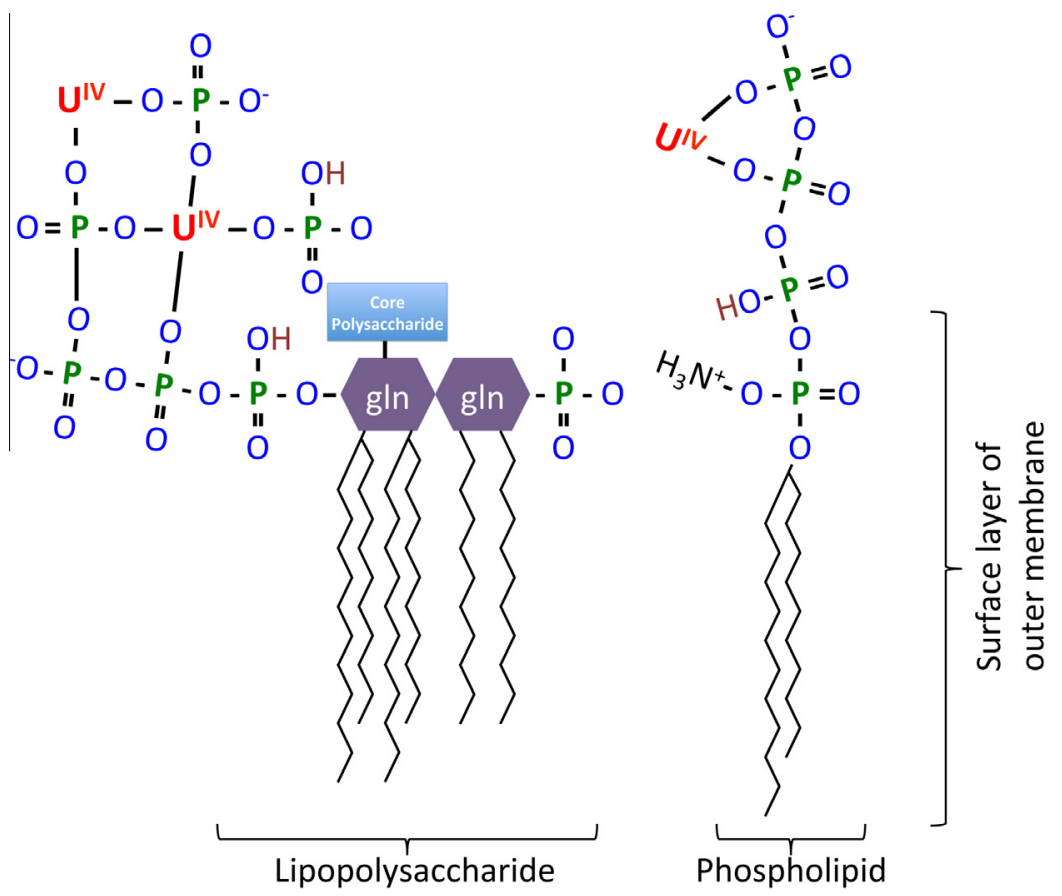

Fig. 6. Conceptual model of the development of phosphate coordination polymers at the surface of cell outer membranes, with bonded noncrystalline U(IV) species. A single representative lipopolysaccharide and phospholipid each is shown. The gln abbreviation refers to glucosamine.

by cell lysis or the phosphate-containing biomolecules loosely associated with the cells. A conceptual model of noncrystalline U(IV) associated with a phosphate coordination polymer that originates at the cell membrane is illustrated in Fig. 6. U(IV) produced from enzymatic U(VI) reduction near the cell membrane would preferably bind to the excess phosphate groups, precluding the precipitation of biogenic uraninite nanoparticles and ultimately resulting in a phosphate coordination polymer decorated with U(IV).

\section{CONCLUSIONS}

It is now established that, in addition to crystalline uraninite, noncrystalline U(IV) species may form as the product of microbial $\mathrm{U}(\mathrm{VI})$ reduction in aquifers at uranium contaminated field sites (Campbell et al., 2011; Bargar et al., 2013). Due to the relatively higher lability of noncrystalline U(IV) (Alessi et al., 2012), unraveling its structure is critical to providing some understanding of conditions promoting its formation. Previous studies have established that the ratio of uraninite to noncrystalline $\mathrm{U}(\mathrm{IV})$ formed is strongly impacted by the ions present in the reduction solution or medium (Bernier-Latmani et al., 2010; Boyanov et al., 2011; Stylo et al., 2013) and have hypothesized that noncrystalline U(IV) species were coordinated to phosphate by inferring the possibility from fitting of $\mathrm{U} \mathrm{L}_{\mathrm{III}}$-edge EXAFS spectra and evidence of $\mathrm{U}(\mathrm{IV})$ and $\mathrm{P}$ co-occurrence from elemental mapping during electron microscopy analyses (Bernier-Latmani et al., 2010). Here, using combined spectroscopy and wet chemical techniques, we have demonstrated unambiguously that noncrystalline $\mathrm{U}(\mathrm{IV})$ is comprised of multiple U(IV) species bonded to phosphate groups. Some species are associated with phosphate functional groups in the microbial biomass as either monomers or polymers while others form through the precipitation of inorganic phosphate polymers that are more difficult to extract using a concentrated bicarbonate solution. There is strong evidence that $\mathrm{U}(\mathrm{IV})$ is coordinated to polymerized phosphate, i.e., that U(IV) coordination polymers are present, based on combined IR spectroscopy and P K-edge XANES analyses, and supported by $\mathrm{U} \mathrm{L}_{\mathrm{III}}$-edge EXAFS shell-by-shell fitting. Because the FTIR analysis is sensitive to changes in the relative intensity of the amide I and II bands, it is also possible to detect a clear signal for a shift in protein composition as a result of the presence of $U$. This finding echoes previous transcriptomic work (BencheikhLatmani et al., 2005) and suggests a toxicity response of $S$. oneidensis cells to $\mathrm{U}$ that includes increased production of phosphate-rich EPS that contains binding sites for U(IV) (Bernier-Latmani et al., 2013; Stylo et al., 2013). Our work points to the simultaneous formation of a spectrum of $\mathrm{U}(\mathrm{IV})$-containing species, including fractions of biogenic uraninite as determined by combined U EXAFS analyses and bicarbonate extractions (Alessi et al., 2012), noncrystalline U(IV) species that occur as phosphate coordination polymers or biomass-associated monomers, and U(IV)-phosphate precipitates such as ningyoite (Bernier-Latmani et al., 2010; Rui et al., 2013). Our work provides a significant step in unraveling the nature of biomass-associated noncrystalline U(IV) species.

\section{ACKNOWLEDGMENTS}

Work carried out at EPFL was funded by Swiss NSF grants No. 200021-113784 and 200020-126821, SNSF International 
Co-operation grant No. IZK0Z2-12355, SNSF International Short Visits grant No. IZK0Z2-133214 and the SLAC Science Focus Area (work package 10094) funded by the USDOE Office of Biological and Environmental Research, Subsurface Biogeochemical Research program. DSA was partially supported by a Marie Curie International Incoming Fellowship from the European Commission, grant FP7-PEOPLE-2009-IIF-254143. Portions of this research were carried out at the Stanford Synchrotron Radiation Lightsource, a national user facility operated by Stanford University on behalf of the U.S. Department of Energy (DOE), Office of Basic Energy Sciences. The SSRL Structural Molecular Biology Program is supported by the Department of Energy, Office of Biological and Environmental Research, and by the National Institutes of Health, National Center for Research Resources, Biomedical Technology Program. The P K-edge measurements were performed on the PHOENIX beamline of the Swiss Light Source (SLS, Paul Scherrer Institut, Villigen, Switzerland). We thank Dr. András Gorzsás of Umeå University for conducting some of the FTIR measurements.

\section{APPENDIX A. SUPPLEMENTARY DATA}

Supplementary data associated with this article can be found, in the online version, at http://dx.doi.org/10.1016/ j.gca.2014.01.005.

\section{REFERENCES}

Alessi D. S., Uster B., Veeramani H., Suvorova E. I., LezamaPacheco J. S., Stubbs J. E., Bargar J. R. and Bernier-Latmani R. (2012) Quantitative separation of monomeric U(IV) from $\mathrm{UO}_{2}$ in products of $\mathrm{U}(\mathrm{VI})$ reduction. Environ. Sci. Technol. 46, 6150-6157.

Alessi D. S., Uster B., Borca C. N., Grolimund D. and BernierLatmani R. (2013) Beam induced oxidation of monomeric U(IV) species. J. Synchrotron Radiat. 20, 197-199.

Bargar J. R., Bernier-Latmani R., Giammar D. E. and Tebo B. M. (2008) Biogenic uraninite nanoparticles and their importance for uranium remediation. Elements 4(6), 407-412.

Bargar J. R., Williams K. H., Campbell K. M., Long P. E., Stubbs J. E., Suvorova E., Lezama-Pacheco J. S., Alessi D. S., Stylo M., Webb S. M., Davis J. A., Giammar D. E., Blue L. Y. and Bernier-Latmani R. (2013) Uranium redox transition pathways in acetate-amended sediments. Proc. Natl. Acad. Sci. USA 110(12), 4506-4511.

Bencheikh-Latmani R., Middleton Williams S., Haucke L., Criddle C. S., Wu L., Zhou J. and Tebo B. M. (2005) Global transcriptional profiling of Shewanella oneidensis MR-1 during $\mathrm{Cr}(\mathrm{VI})$ and $\mathrm{U}(\mathrm{VI})$ reduction. Appl. Environ. Microbiol. 71, 7453-7460.

Bernier-Latmani R., Veeramani H., Dalla Vecchia E., Junier P., Lezama-Pacheco J. S., Suvorova E. I., Sharp J. O., Wigginton N. S. and Bargar J. R. (2010) Non-uraninite products of microbial U(VI) reduction. Environ. Sci. Technol. 44, 94569462.

Bernier-Latmani R., Shao P. P., Comolli L. R., Stylo M., Alessi D. S. and Bargar J. R. (2013) Extracellular polymeric substances modulate the product of uranium biomineralization. Mineral. Mag. 77, 693.

Boyanov M. I., Fletcher K. E., Kwon M. J., Rui X., O'Loughlin E. J., Löffler F. E. and Kemner K. M. (2011) Solution and microbial controls on the formation of reduced U(IV) species. Environ. Sci. Technol. 45, 8336-8344.
Brandes J. A., Ingall E. and Paterson D. (2007) Characterization of minerals and organic phosphorus species in marine sediments using soft X-ray fluorescence spectromicroscopy. Mar. Chem. 103, 250-265.

Burgos W. D., McDonough J. T., Senko J. M., Zhang G. X., Dohnalkova A. C., Kelly S. D., Gorby Y. and Kemner K. M. (2008) Characterization of uraninite nanoparticles produced by Shewanella oneidensis MR-1. Geochim. Cosmochim. Acta 72, 4901-4915.

Burns P. C. (1999) The crystal chemistry of uranium. In Uranium: Mineralogy, Chemistry and the Environment (eds. P. C. Burns and R. Finch). Mineralogical Society of America, Washington, DC, pp. 23-90.

Campbell K. M., Davis J. A., Bargar J., Giammar D., BernierLatmani R., Kukkadapu R., Williams K. H., Veeramani H., Ulrich K.-U., Stubbs J., Yabusaki S., Figueroa L., Lesher E., Wilkins M. J., Peacock A. and Long P. E. (2011) Composition, stability, and measurement of reduced uranium phases for groundwater bioremediation at Old Rifle, CO. Appl. Geochem. 26, S167-S169.

Cao B., Shi L., Brown R. N., Xiong Y., Fredrickson J. K., Romine M. F., Marshall M. J., Lipton M. S. and Beyenal H. (2011) Extracellular polymeric substances from Shewanella sp. HRCR1 biofilms: characterization by infrared spectroscopy and proteomics. Environ. Microbiol. 13, 1018-1031.

Cerrato J. M., Ashner M. N., Alessi D. S., Lezama-Pacheco J. S., Bernier-Latmani R., Bargar J. R. and Giammar D. E. (2013) Relative reactivity of biogenic and chemogenic uraninite and biogenic noncrystalline U(IV). Environ. Sci. Technol. 47, 9756 9763.

Chakraborty S., Favre F., Banerjee D., Scheinost A. C., Mullet M., Ehrhardt J.-J., Brendle J., Vidal L. and Charlet L. (2010) U(VI) sorption and reduction by $\mathrm{Fe}(\mathrm{II})$ sorbed on montmorillonite. Environ. Sci. Technol. 44, 3779-3785.

Cologgi D. L., Lampa-Pastirk S., Speers A. M., Kelly S. D. and Reguera G. (2011) Extracellular reduction of uranium via Geobacter conductive pili as a protective cellular mechanism. Proc. Natl. Acad. Sci. USA 108, 15248-15252.

Flemming H.-C., Neu T. R. and Wozniak D. J. (2007) The EPS matrix: the "House of Biofilm Cells". J. Bacteriol. 189, 79457947.

Flemming H.-C. and Wingender J. (2010) The biofilm matrix. Nat. Rev. Microbiol. 8, 623-633.

Fletcher K. E., Boyanov M. I., Thomas S. H., Wu Q. Z., Kemner K. M. and Löffler F. E. (2010) U(VI) reduction to mononuclear U(IV) by Desulfitobacterium species. Environ. Sci. Technol. 44, 4705-4709.

Franke R. and Hormes J. (1995) The P K-near edge absorption spectra of phosphates. Physica B 216, 85-95.

George G. N. (1993) X-ray absorption spectroscopy of light elements in biological systems. Curr. Opin. Struct. Biol. 3, 780-784.

Hesterberg D. (2010) Macroscale chemical properties and X-ray absorption spectroscopy of soil phosphorus. In SynchrotronBased Techniques in Soils and Sediments (eds. B. Singh and M. Gräfe). Elsevier, Amsterdam, Netherlands, pp. 313-356.

Ingall E. D., Brandes J. A., Diaz J. M., de Jonge M. D., Paterson D., McNulty I., Elliott W. C. and Northrup P. (2011) Phosphorus $K$-edge XANES spectroscopy of mineral standards. J. Synchrotron Radiat. 18, 189-197.

Jeon B.-H., Dempsey B. A., Burgos W. D., Barnett M. O. and Roden E. E. (2005) Chemical reduction of U(VI) by Fe(II) at the solid-water interface using natural and synthetic Fe(III) oxides. Environ. Sci. Technol. 39, 5642-5649.

Jiang W., Saxena A., Song B., Ward B. B., Beveridge T. J. and Myneni S. C. B. (2004) Elucidation of functional groups on 
gram-positive and gram-negative bacterial surfaces using infrared spectroscopy. Langmuir 20, 11433-11442.

Kelly S. D., Hesterberg D. and Ravel B. (2008) Analysis of soils and minerals using X-ray absorption spectroscopy. In Methods of Soil Analysis. Part 5. Mineralogical Methods (eds. A. L. Ulery and R. Drees). Soil Sci. Soc. Am., Madison, WI, pp. 387463.

Khijniak T. V., Slobodkin A. I., Coker V., Renshaw J. C., Livens F. R., Bonch-Osmolovskaya E. A., Birkeland N.-K., Medvedeva-Lyalikova N. N. and Lloyd J. R. (2005) Reduction of uranium(VI) phosphate during growth of the thermophilic bacterium Thermoterrabacterium ferrireducens. Appl. Environ. Microbiol. 71, 6423-6426.

Kim J.-G., Park Y.-S., Ha Y.-K. and Song K. (2012) Infrared spectra of uranium oxides measured by ATR-FTIR. J. Nucl. Sci. Technol. 46, 1188-1192.

Korenevsky A. A., Vinogradov E., Gorby Y. and Beveridge T. J. (2002) Characterization of the lipopolysaccharides and capsules of Shewanella spp.. Appl. Environ. Microbiol. 68, 4653-4657.

Langley S. and Beveridge T. J. (1999) Effect of O-side-chainlipopolysaccharide chemistry on metal binding. Appl. Environ. Microbiol. 65, 489-498.

Latta D. E., Boyanov M. I., Kemner K. M., O’Loughlin E. J. and Scherer M. M. (2012) Abiotic reduction of uranium by Fe(II) in soil. Appl. Geochem. 27, 1512-1524.

Leone L., Ferri D., Manfredi C., Persson P., Shchukarev A., Sjöberg S. and Loring J. (2007) Modeling the acid-base properties of bacterial surfaces: a combined spectroscopic and potentiometric study of the Gram-positive bacterium Bacillus subtilis. Environ. Sci. Technol. 41, 6465-6471.

Lovley D. R., Phillips E. J. P., Gorby Y. A. and Landa E. R. (1991) Microbial reduction of uranium. Nature 350, 413-416.

Lovley D. R. and Phillips E. J. P. (1992) Reduction of uranium by Desulfovibrio desulfuricans. Appl. Environ. Microbiol. 58, 850856.

Lovley D. R. (1993) Dissimilatory metal reduction. Аnпи. Rev. Microbiol. 47, 263-290.

McCrate O. A., Zhou X., Reichhard C. and Cegelski L. (2013) Sum of the parts: composition and architecture of the bacterial extracellular matrix. J. Mol. Biol. 425, 4286-4294.

O'Loughlin E. J., Kelly S. D., Cook R. E., Csencsits R. and Kemner K. M. (2003) Reduction of uranium (VI) by mixed iron(II)/iron(III) hydroxide (green rust): formation of $\mathrm{UO}_{2}$ nanoparticles. Environ. Sci. Technol. 37, 721-727.

Podor R., François M. and Dacheux N. (2003) Synthesis, characterization, and structure determination of the orthorhombic $\mathrm{U}_{2}\left(\mathrm{PO}_{4}\right)\left(\mathrm{P}_{3} \mathrm{O}_{10}\right)$. J. Solid State Chem. 172, 66-72.

Ravel B. and Newville M. (2005) Athena, artemis, hephaestus: data analysis for X-ray absorption spectroscopy using IFEFFIT. $J$. Synchrotron Radiat. 12, 537-541.

Ray A. E., Bargar J. R., Sivaswamy V., Dohnalkova A., Fujita Y., Peyton B. M. and Magnuson T. S. (2011) Evidence for multiple modes of uranium immobilization by an anaerobic bacterium. Geochim. Cosmochim. Acta 75, 2684-2695.

Rehr J. J., Albers R. C. and Zabinsky S. I. (1992) High-order multiple-scattering calculations of X-ray-absorption fine-structure. Phys. Rev. Lett. 69, 3397-3400.

Rui X., Kwon M. J., O'Loughlin E. J., Dunham-Cheatham S., Fein J. B., Bunker B., Kemner K. M. and Boyanov M. I. (2013) Bioreduction of hydrogen uranyl phosphate: mechanisms and U(IV) products. Environ. Sci. Technol. 47, 5668-5678.

Schofield E. J., Veeramani H., Sharp J. O., Suvorova E., BernierLatmani R., Mehta A., Stahlman J., Webb S. M., Clark D. L., Conradson S. D., Ilton E. S. and Bargar J. R. (2008) Structure of biogenic uraninite produced by Shewanella oneidensis strain MR-1. Environ. Sci. Technol. 42, 7898-7904.

Senko J. M., Kelly S. D., Dohnalkova A. C., McDonough J. T., Kemner K. M. and Burgos W. D. (2007) The effect of U(VI) bioreduction kinetics on subsequent reoxidation of biogenic U(IV). Geochim. Cosmochim. Acta 71, 4644-4654.

Sharp J. O., Lezama-Pacheco J. S., Schofield E. J., Junier P., Ulrich K.-U., Chinni S., Veeramani H., Margot-Roquier C., Webb S. M., Tebo B. M., Giammar D. E., Bargar J. R. and BernierLatmani R. (2011) Uranium speciation and stability after reductive immobilization in aquifer sediments. Geochim. Cosmochim. Acta 75, 6497-6510.

Sheng L., Szymanowksi J. and Fein J. B. (2011) The effects of uranium speciation on the rate of $\mathrm{U}(\mathrm{VI})$ reduction by Shewanella oneidensis MR-1. Geochim. Cosmochim. Acta 75, 35583567 .

Sivaswamy V., Boyanov M. I., Peyton B. M., Viamajala S., Gerlach R., Apel W. A., Sani R. K., Dohnalkova A., Kemner K. M. and Borch T. (2011) Multiple mechanisms of uranium immobilization by Cellulomonas sp. strain ES6. Biotechnol. Bioeng. 108, 264-276.

Stylo M., Alessi D. S., Shao P. P.-Y., Lezama-Pacheco J., Bargar J. and Bernier-Latmani R. (2013) Biogeochemical controls on the product of microbial U(VI) reduction. Environ. Sci. Technol. 47, 12351-12358.

Toor G. S., Hunger S., Peak J. D., Sims J. T. and Sparks D. L. (2006) Advances in the characterization of phosphorus in organic wastes: environmental and agronomic applications. Adv. Agron. 89, 1-72.

Veeramani H., Alessi D. S., Suvorova E. I., Lezama-Pacheco J. S., Stubbs J. E., Sharp J. O., Dippon U., Kappler A., Bargar J. R. and Bernier-Latmani R. (2011) Products of abiotic U(VI) reduction by biogenic magnetite and vivianite. Geochim. Cosmochim. Acta 75, 2512-2528.

Veeramani H., Scheinost A. C., Monsegue N., Qafoku N. P., Kukkapadu R., Newville M., Lanzirotti A., Pruden A., Murayama M. and Hochella M. F. (2013) Abiotic reductive immobilization of U(VI) by biogenic mackinawite. Environ. Sci. Technol. 47, 2361-2369.

Vinogradov E., Korenevsky A. and Beveridge T. J. (2003) The structure of the rough-type lipopolysaccharide from Shewanella oneidensis MR-1, containing 8-amino-8-deoxy-Kdo and an open-chain form of 2-acetamido-2-deoxy-D-galactose. Carbohyd. Res. 338, 1991-1997.

Wall J. D. and Krumholz L. R. (2006) Uranium reduction. Annu. Rev. Microbiol. 60, 149-166.

Wang H., Hollywood K., Jarvis R. M., Lloyd J. R. and Goodacre R. (2010) Penotypic characterization of Shewanella oneidensis MR-1 by using Fourier transform infrared spectroscopy and high-performance liquid chromatography analyses. Appl. Environ. Microbiol. 76, 6266-6276.

Webb S. M. (2005) SIXPACK: a graphical user interface for XAS analysis using IFEFFIT. Phys. Scripta T115, 1011-1014.

Yeh H. Y., Price R. M. and Jacobs D. M. (1992) Use of ophthalaldehyde to detect O-phosphorylethanolamine in bacterial lipopolysaccharide. AMPIS 100, 503-508.

Zhang G., Burgos W. D., Senko J. M., Bishop M. E., Dong H., Boyanov M. I. and Kemner K. M. (2011) Microbial reduction of chlorite and uranium followed by air oxidation. Chem. Geol. 238, 242-250.

Associate editor: John Moreau 